\title{
Arrhenius Activation Parameters for the Loss of Neutral Nucleobases from Deprotonated Oligonucleotide Anions in the Gas Phase
}

\author{
Rambod Daneshfar and John S. Klassen \\ Department of Chemistry, University of Alberta, Edmonton, Alberta, Canada
}

\begin{abstract}
Arrhenius activation parameters $\left(E_{a}\right.$ and $A$ ) for the loss of neutral nucleobase from a series of doubly deprotonated oligodexoynucleotide 10-mers of the type $\mathrm{XT}_{9}, \mathrm{~T}_{9} \mathrm{X}$, and $\mathrm{T}_{5} \mathrm{XT}_{4}$, where $\mathrm{X}$ $=\mathrm{A}, \mathrm{C}$, and $\mathrm{G}$, have been determined using the blackbody infrared radiative dissociation technique. At temperatures of 120 to $190{ }^{\circ} \mathrm{C}$, the anions dissociate exclusively by the loss of a neutral nucleobase $(\mathrm{XH})$, followed by cleavage of the sugar $3^{\prime} \mathrm{C}-\mathrm{O}$ bond leading to $(\mathrm{a}-\mathrm{XH})$ and $\mathrm{w}$ type ions or, in the case of the $\mathrm{T}_{9} \mathrm{X}^{2-}$ ions, the loss of $\mathrm{H}_{2} \mathrm{O}$. The dissociation kinetics and energetics are sensitive to the nature and position of $\mathrm{X}$. Over the temperature range investigated, the kinetics for the loss of $\mathrm{AH}$ and $\mathrm{GH}$ were similar, but $\sim 100$ times faster than for the loss of $\mathrm{CH}$. For the loss of $\mathrm{AH}$ and $\mathrm{GH}$, the values of $E_{a}$ are sensitive to the position of the base. The order of the $E_{a}$ s for the loss of $\mathrm{XH}$ from the $5^{\prime}$ and $3^{\prime}$ termini is: $\mathrm{C}>\mathrm{G}>\mathrm{A}$; while for $\mathrm{T}_{5} \mathrm{XT}_{4}$ the order is: $\mathrm{C}>\mathrm{A}>\mathrm{G}$. The trends in the values of $E_{a}$ do not parallel the trend in deprotonation enthalpies or proton affinities of the nucleobases in the gas phase, indicating that the energetic differences do not simply reflect differences in their gas phase acidity or basicity. The pre-exponential factors $(A)$ vary from $10^{10}$ to $10^{15} \mathrm{~s}^{-1}$, depending on the nature and position of $X$. These results suggest that the reactivity of individual nucleobases is influenced by stabilizing intramolecular interactions. (J Am Soc Mass Spectrom 2004, 15, 55-64) (c) 2004 American Society for Mass Spectrometry
\end{abstract}

$\mathrm{M}$ ass spectrometry (MS), combined with soft ionization techniques such as electrospray (ES) and matrix assisted laser desorption/ ionization (MALDI), has become an indispensable tool for identifying the primary structure (sequence) of biopolymers: peptides, oligosaccharides, and oligonucleotides. The mass spectrometry-based sequencing approach typically involves isolating the biopolymer ion of interest in the gas phase, dissociating it to produce sequence specific fragment ions and accurately determining the mass of the ions. Sequence information is extracted from the mass differences of the sequential fragment ions of the same general structure. The MSbased sequencing approach has many attractive features, most notably its inherent speed and sensitivity and its ability to sequence biopolymers containing unnatural or unusual modifications. Despite its widespread use in the sequencing of biopolymers, fundamental questions regarding the gas phase dissociation mechanisms remain. Elucidating these mechanisms is of practical importance, since it will facilitate the ratio-

Published online November 19, 2003

Address reprint requests to Dr. J. S. Klassen, Department of Chemistry, University of Alberta, Edmonton, Alberta T6G 2G2, Canada. E-mail: john.klassen@ualberta.ca nal development of MS-based techniques for sequencing. In addition, the dissociation of biomolecules in the gas phase reflects their intrinsic properties, which are of fundamental interest.

For oligodeoxynucleotides (ODNs), sequence information can be obtained from the fragmentation behaviour of either the protonated or deprotonated gaseous ions and the dissociation behaviour of both forms has been extensively investigated [1-10]. The dissociation of deprotonated ODNs, the focus of the present study, has been shown to proceed first by the loss of a nucleobase, adenine $(A)$, guanine $(G)$, cytosine $(C)$ or thymine $(T)$, in its neutral or deprotonated form, followed by fragmentation of the phosphoester bond at the deoxyribose $3^{\prime}$ $\mathrm{C}-\mathrm{O}$ bond at the site of base loss to produce (a-base) and $\mathrm{w}$ type ions, according to the nomenclature proposed by McLuckey and coworkers [7].

For ODN anions in low charge states, the nucleobases are lost in their neutral form. Interestingly, a survey of the literature reveals that the reactivity of the bases is highly variable and influenced by the sequence and charge state, and, seemingly, the activation technique. For example, Gross and coworkers examined the reactivity of the different bases in doubly deprotonated T-rich 8-mers using collision-induced dissociation (CID) implemented in an ion trap mass spectrometer 
(ITMS) [11]. The tendency to lose a given base and form the corresponding (a-base) ion was found to have the following order: $\mathrm{G}>\mathrm{C} \approx \mathrm{A} \gg \mathrm{T}$. A similar trend was observed by Smith and coworkers for the -2 and -3 charge states of a number of 12 mers [12]. However, in this same study the authors noted different trends at higher charge states: $\mathrm{A}>\mathrm{C} \approx \mathrm{G} \gg \mathrm{T}(-4) ; \mathrm{A}>\mathrm{C}>\mathrm{G} \gg$ $\mathrm{T}(-5)$. McLafferty and coworkers, using infrared multiphoton dissociation (IRMPD) and CID implemented with a Fourier transform ion cyclotron resonance mass spectrometer (FT-ICR/MS), observed the following trend for large multiply deprotonated oligonucleotides (up to 100 mers): $\mathrm{A}>\mathrm{C} \approx \mathrm{G} \gg \mathrm{T}$ [9]. In contrast, McLuckey et al. did not observe any preferential loss of the nucleobases in CID-ITMS experiments perform on small, but relatively highly charged, ODN anions (4-, 5and 8-mers) [8].

At present, the origin of the differential reactivity of the nucleobases is not fully understood. A number of mechanisms have been proposed to account for the loss of neutral base and subsequent backbone fragmentation and these have been summarized by Gross and coworkers $[11,13]$. Briefly, the proposed mechanisms involve either the loss of the nucleobase in its deprotonated form, followed by proton abstraction from the ODN such that the base is ultimately lost as a neutral, or the loss of the nucleobase in its neutral form, which requires proton transfer either before or in concert with cleavage of the N-glycosidic linkage. It has been suggested that these two general mechanisms might be distinguished based on a correlation between the dissociation energetics of the different nucleobases and their proton affinity (PA), if the base is protonated prior to cleavage of the glycosidic bond [11, 13-15], or their gas phase deprotonation enthalpy $\left(\Delta \mathrm{H}_{\text {acid }}\right)[2,10,16$, 17], if the base is lost in its deprotonated form. To date, however, there are few energetic data available for the loss of nucleobases from ODN anions with which to compare the thermodynamic acid/base properties. Consequently, the relative dissociation energies have been inferred from trends in the dissociation kinetics, normally established from CID experiments. For example, Gross and coworkers have suggested that correlation of the reactivity of bases (determined by CID) and their PAs as evidence for a dissociation mechanism in which the nucleobase abstracts a proton prior to cleavage of the N-glycosidic bond [11]. However, trends in dissociation kinetics are generally not reliable indicators of the relative dissociation energetics, particularly when the internal energy distribution of the reactant ions is unknown, as is typically the case in CID experiments.

The first quantitative study of the dissociation kinetics and energetics of deprotonated ODNs was performed by Williams and coworkers [16]. Using the blackbody infrared radiative dissociation (BIRD) technique and FT-ICR/MS, they determined Arrhenius activation parameters for the loss of neutral $\mathrm{AH}, \mathrm{CH}$ and $\mathrm{GH}$ from a small number of doubly deprotonated 7 mers. However, all of the oligonucleotides investigated contained multiple reactive bases and the values of $E_{a}$ reported in this work represent average values, reflecting base loss from multiple sites. These authors also reported that thymine was stable, independent of sequence, at temperatures up to $210{ }^{\circ} \mathrm{C}$. Recently, Muddiman and coworkers used IRMPD experiments to investigate the relative energetics for the loss of neutral base from some triply deprotonated 16-mers [18]. The relative energetics established for multiple reactive bases were in good agreement with the aforementioned BIRD study. The present work represents the first systematic study of the kinetics and energetics for the loss of neutral nucleobase from a series of doubly deprotonated T-rich ODN 10-mers, $\mathrm{XT}_{9}, \mathrm{~T}_{9} \mathrm{X}$, and $\mathrm{T}_{5} \mathrm{XT}_{4}$, containing a single reactive base $(X=A, C$, or $G)$. Time-resolved BIRD experiments have been used to evaluate the dissociation kinetics for the loss of $\mathrm{XH}$. From the temperature dependence of the dissociation rate constants, Arrhenius activation parameters have been determined. The trends in the kinetics and energetics for the loss of nucleobase are compared with trends reported in previous dissociation studies and discussed in terms of possible dissociation mechanisms and the presence of internal solvation of the reactive base.

\section{Experimental}

The experimental apparatus and procedures used in this work have been described in detail elsewhere [19] and only a brief overview is given here. All experiments were performed on an ApexII 47e Fourier transform ion cyclotron resonance (FT-ICR) mass spectrometer (Bruker, Billerica, MA) equipped with a modified external nanoelectrospray (nanoES) ion source. The oligonucleotides were purchased from ACGT Corp. (Toronto, Canada) and used without further purification. The oligonucleotides were dissolved in 1:1 solutions of $\mathrm{H}_{2} \mathrm{O} / \mathrm{CH}_{3} \mathrm{CN}$ at a concentration of $200 \mu \mathrm{M}$. NanoES tips were pulled from aluminosilicate tubes ( $1 \mathrm{~mm}$ o.d., $0.68 \mathrm{~mm}$ i.d.) using a P-97 micropipette puller (Sutter Instruments, Novato, CA). A platinum (Pt) wire, inserted into the open end of the nanoES tip, was used to apply an approximately $-800 \mathrm{~V}$ potential to the nanoES solution. The tip was positioned 1-2 $\mathrm{mm}$ from a stainless steel sampling capillary using a microelectrode holder. The solution flow rate typically ranged from 60 to $100 \mathrm{~nL} / \mathrm{min}$ depending on the diameter of the nanoES tip and the electrospray voltage.

The droplets and gaseous ions produced by nanoES were introduced into the mass spectrometer through a heated stainless steel capillary maintained at a temperature (external) of approximately $70{ }^{\circ} \mathrm{C}$. Ions were accumulated in the external hexapole for $3 \mathrm{~s}$, subsequently ejected and injected at $2700 \mathrm{~V}$ into the bore of the 4.7 tesla superconducting magnet, decelerated and introduced into the ion cell. The temperature of the ion cell was controlled with two external flexible heating blankets placed around the vacuum tube in the vicinity of the ion cell. Mass spectra were acquired by an SGI 


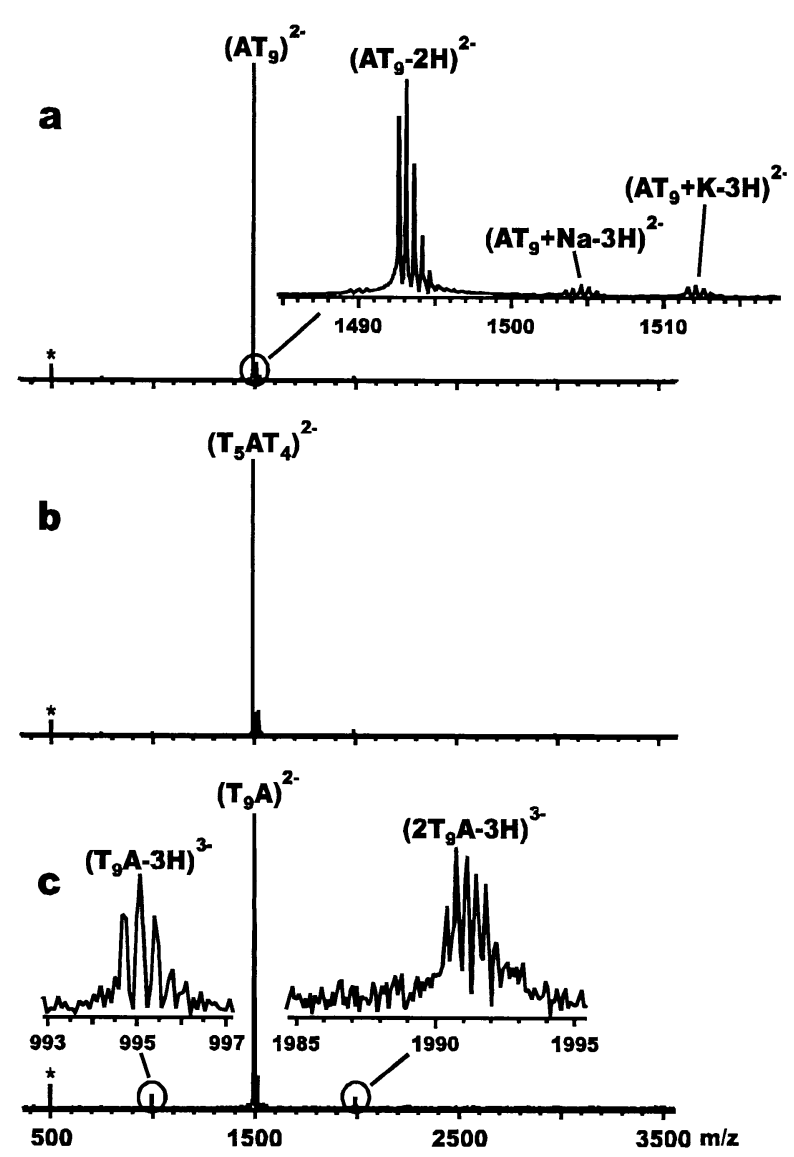

Figure 1. NanoES mass spectra of $1: 1 \mathrm{H}_{2} \mathrm{O}: \mathrm{CH}_{3} \mathrm{CN}$ solutions containing $\sim 10^{-4} \mathrm{M}$ (a) $\mathrm{AT}_{9}$, (b) $\mathrm{T}_{5} \mathrm{AT}_{4}$, (c) $\mathrm{T}_{9} \mathrm{~A}$. The asterisk indicates a harmonic of the precursor ion [31].

R5000 computer running the Bruker Daltonics XMASS software, version 5.0. On average 10 scans, containing $128 \mathrm{~K}$ data points per scan, were acquired per spectrum.

\section{Results and Discussion}

\section{Dissociation Pathways}

NanoES of 1:1 $\mathrm{H}_{2} \mathrm{O}: \mathrm{CH}_{3} \mathrm{CN}$ solutions containing $\sim 10^{-4}$ $\mathrm{M}$ ODN $\left(\mathrm{XT}_{9}, \mathrm{~T}_{5} \mathrm{XT}_{4}\right.$, or $\mathrm{T}_{9} \mathrm{X}$, where $\mathrm{X}=\mathrm{A}, \mathrm{C}$, or $\left.\mathrm{G}\right)$ produced almost exclusively the doubly deprotonated ion $(\mathrm{M}-2 \mathrm{H})^{2-}$ with small amounts of the $\mathrm{Na}^{+}$and $\mathrm{K}^{+}$ adducts, see Figure 1. A small amount of the triply deprotonated $(\mathrm{M}-3 \mathrm{H})^{3-}$ ion and the nonspecific dimer, $(2 \mathrm{M}-3 \mathrm{H})^{3-}$, were also frequently observed. BIRD was performed on the $(\mathrm{M}-2 \mathrm{H})^{2-}\left(\equiv \mathrm{M}^{2-}\right)$ ions at temperatures ranging from 120 to $190{ }^{\circ} \mathrm{C}$. Representative BIRD spectra for each $\mathrm{M}^{2-}$ ion are shown in Figure 2. Dissociation of the $\left(\mathrm{XT}_{9}\right)^{2-}$ and $\left(\mathrm{T}_{5} \mathrm{XT}_{4}\right)^{2-}$ ions, where $\mathrm{X}=\mathrm{A}$ or $\mathrm{G}$, yielded product ions corresponding to the loss of neutral base, $(\mathrm{M}-\mathrm{XH})^{2-}$, and cleavage of the sugar 3' $\mathrm{C}-\mathrm{O}$ bond, leading to the $\mathrm{w}_{9}^{2-}$ ion for $\left(\mathrm{XT}_{9}\right)^{2-}$ and the complementary $\left(\mathrm{a}_{6}-\mathrm{XH}\right)^{-}$and $\mathrm{w}_{4}^{-}$ions for $\left(\mathrm{T}_{5} \mathrm{XT}_{4}\right)^{2-}$. Dissociation of the $\left(\mathrm{T}_{9} \mathrm{X}\right)^{2-}$ ions $(\mathrm{X}=\mathrm{A}$ or $\mathrm{G})$, resulted in the $(\mathrm{M}-\mathrm{XH})^{2-}$ and $\left(\mathrm{M}-\mathrm{XH}-\mathrm{H}_{2} \mathrm{O}\right)^{2-}$ (structurally equivalent to $\left.\left(\mathrm{a}_{10}-\mathrm{XH}\right)^{2-}\right)$ ions. The same product ions were observed for the $\mathrm{C}$-containing anions, with the exception of the $(\mathrm{M}-\mathrm{XH})^{2-}$ ion, which is believed to have a short lifetime under the experimental conditions used, vide infra. There was no indication of the loss of neutral thymine in any of the spectra, consistent with the results reported in the previous BIRD study [16].

There is abundant experimental evidence that the loss of neutral base precedes backbone fragmentation in ODN anions in low charge states. For example, from the absence of product ions in the BIRD spectra of several doubly deprotonated 7-mers, acquired with the continuous ejection of the $(\mathrm{M}-\mathrm{XH})^{2-}$ ion (i.e., double resonance experiments), Williams and coworkers demonstrated conclusively that the loss of $\mathrm{XH}$ (where $\mathrm{X}=$ A, C, and G) represented the only primary dissociation channel at temperatures $<210{ }^{\circ} \mathrm{C}$, with all other fragment ions originating from the $(\mathrm{M}-\mathrm{XH})^{2-}$ ion [16]. Beauchamp and coworkers reported similar results for deprotonated dinucleotide ions [10]. Based on these and related studies it is reasonable to expect the 10-mers investigated here to react in a similar fashion, i.e., loss of neutral base, followed by backbone cleavage (eq 1a-c). However, the absence of the $(\mathrm{M}-\mathrm{CH})^{2-}$ ions in the BIRD spectra of all three C-containing anions was unexpected and raised the possibility of a different dissociation pathway for these ions. To verify that the loss of $\mathrm{CH}$ was in fact the only primary dissociation channel, double resonance experiments were performed on the C-containing 10-mers. All of the expected product ions of $\left(\mathrm{CT}_{9}\right)^{2-},\left(\mathrm{T}_{5} \mathrm{CT}_{4}\right)^{2-}$, and $\left(\mathrm{T}_{9} \mathrm{C}\right)^{2-}$ were absent in the BIRD spectra acquired for experiments in which continuous $\mathrm{rf}$ excitation, at the frequency of the $(\mathrm{M}-\mathrm{CH})^{2-}$ ion $(\nu=50.3 \mathrm{kHz})$, was applied throughout the reaction. The product ions were restored when the frequency of the rf excitation was moved slightly off-resonance from the $(\mathrm{M}-\mathrm{CH})^{2-}$ ion $(\nu=49.8 \mathrm{kHz})$, indicating that the disappearance of the fragment ions was due to the elimination of the only primary product ion rather than the loss of ions due to off-resonance excitation. These results are illustrated for $\left(\mathrm{CT}_{9}\right)^{2-}$ in Figures $3 a, b, c$. The absence of the $(\mathrm{M}-\mathrm{CH})^{2-}$ ions in the BIRD spectra can, therefore, be attributed to the slow dissociation kinetics for the loss of $\mathrm{CH}$, compared with the secondary dissociation processes, such that the lifetimes of the $(\mathrm{M}-\mathrm{CH})^{2-}$ ions are short. Double resonance experiments performed on the A- and Gcontaining ions also confirmed that the loss of neutral base precedes backbone fragmentation.

$$
\begin{aligned}
& \mathrm{XT}_{9}{ }^{2-} \rightarrow\left(\mathrm{XT}_{9}-\mathrm{XH}\right)^{2-} \rightarrow \mathrm{w}_{9}{ }^{2-} \\
& \mathrm{T}_{5} \mathrm{XT}_{4}{ }^{2-} \rightarrow\left(\mathrm{T}_{5} \mathrm{XT}_{4}-\mathrm{XH}\right)^{2-} \rightarrow\left(\mathrm{a}_{6}-\mathrm{XH}\right)^{-}+\mathrm{w}_{4}{ }^{-} \\
& \mathrm{T}_{9} \mathrm{X}^{2-} \rightarrow\left(\mathrm{T}_{9} \mathrm{X}-\mathrm{XH}\right)^{2-} \rightarrow \\
& \left(\mathrm{T}_{9} \mathrm{X}-\mathrm{XH}-\mathrm{H}_{2} \mathrm{O}\right)^{2-} \equiv\left(\mathrm{a}_{10-} \mathrm{XH}\right)^{2-}
\end{aligned}
$$




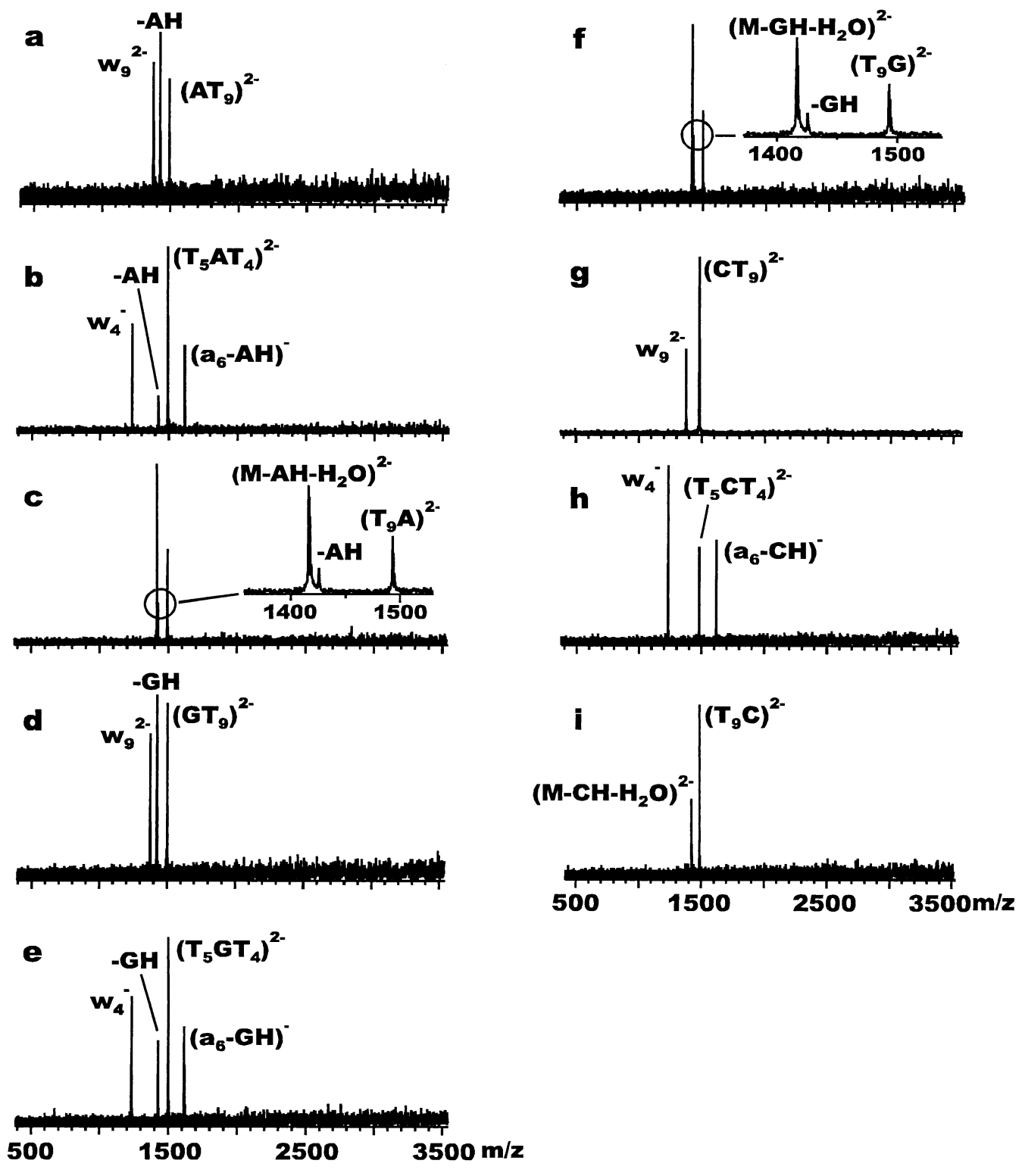

Figure 2. Blackbody infrared radiative dissociation spectra of doubly deprotonated DNA anions (a) $\left(\mathrm{AT}_{9}\right)^{2-}$ at $152.5^{\circ} \mathrm{C}$ and a reaction delay of $18 \mathrm{~s},(\mathbf{b})\left(\mathrm{T}_{5} \mathrm{AT}_{4}\right)^{2-}\left(192.3{ }^{\circ} \mathrm{C}, 3 \mathrm{~s}\right),(\mathbf{c})\left(\mathrm{T}_{9} \mathrm{~A}\right)^{2-}\left(171{ }^{\circ} \mathrm{C}, 9 \mathrm{~s}\right)$, (d) $\left(\mathrm{GT}_{9}\right)^{2-}\left(172{ }^{\circ} \mathrm{C}, 3.75 \mathrm{~s}\right),(\mathbf{e})\left(\mathrm{T}_{5} \mathrm{GT}_{4}\right)^{2-}\left(160.5{ }^{\circ} \mathrm{C}, 15 \mathrm{~s}\right),(\mathbf{f})\left(\mathrm{T}_{9} \mathrm{G}\right)^{2-}\left(134{ }^{\circ} \mathrm{C}, 55 \mathrm{~s}\right),(\mathrm{g})\left(\mathrm{CT}_{9}\right)^{2-}(191.1$ $\left.{ }^{\circ} \mathrm{C}, 50 \mathrm{~s}\right)$, (h) $\left(\mathrm{T}_{5} \mathrm{CT}_{4}\right)^{2-}\left(185.4{ }^{\circ} \mathrm{C}, 600 \mathrm{~s}\right)$, (i) $\left(\mathrm{T}_{9} \mathrm{C}\right)^{2-}\left(192.6{ }^{\circ} \mathrm{C}, 250 \mathrm{~s}\right)$.

\section{Dissociation Kinetics and Arrhenius Parameters}

The temperature dependent first-order rate constant $(k)$ for the loss of neutral nucleobase was determined from the change in the natural log of the normalized intensity (abundance) of the ODN reactant ion $\left(I_{R, \text { norm }}\right)$ with reaction time (eq 2). $I_{R, n o r m}$ was calculated using eq 3, where $I_{R}$ is the abundance of the reactant ion and $\Sigma I_{P}$ is the sum of the abundance of all product ions, including those produced by secondary reactions. Since the total charge of the precursor ion is conserved in the reaction products, the measured intensity of the product and reactant ions was not corrected for charge state. In principle, $I_{R, \text { norm }}$ should be calculated using the sum of the abundance of all the ions (reactant and products) within each isotope envelope. However, in cases where the BIRD spectra exhibit poor signal-to-noise ratio $(\mathrm{S} / \mathrm{N})$ it is difficult to accurately quantify the low abundance isotope peaks. In such cases, $I_{R, \text { norm }}$ was calculated using only the most abundant isotopic ion for the reactant and product ions. Shown in Figure 4a and $b$ is the distribution of the differences in the normalized parent ion abundance obtained using these two approaches for $\left(\mathrm{AT}_{9}\right)^{2-}$ and $\left(\mathrm{T}_{5} \mathrm{AT}_{4}\right)^{2-}$, respectively. It can be seen that the two methods yield similar values of $I_{R, n o r m}$, with differences typically less than $\pm 15 \%$. Consequently, the dissociation rate constants and activation energies should be independent of the method used to calculate $I_{R, \text { norm }}$. Illustrative kinetic 


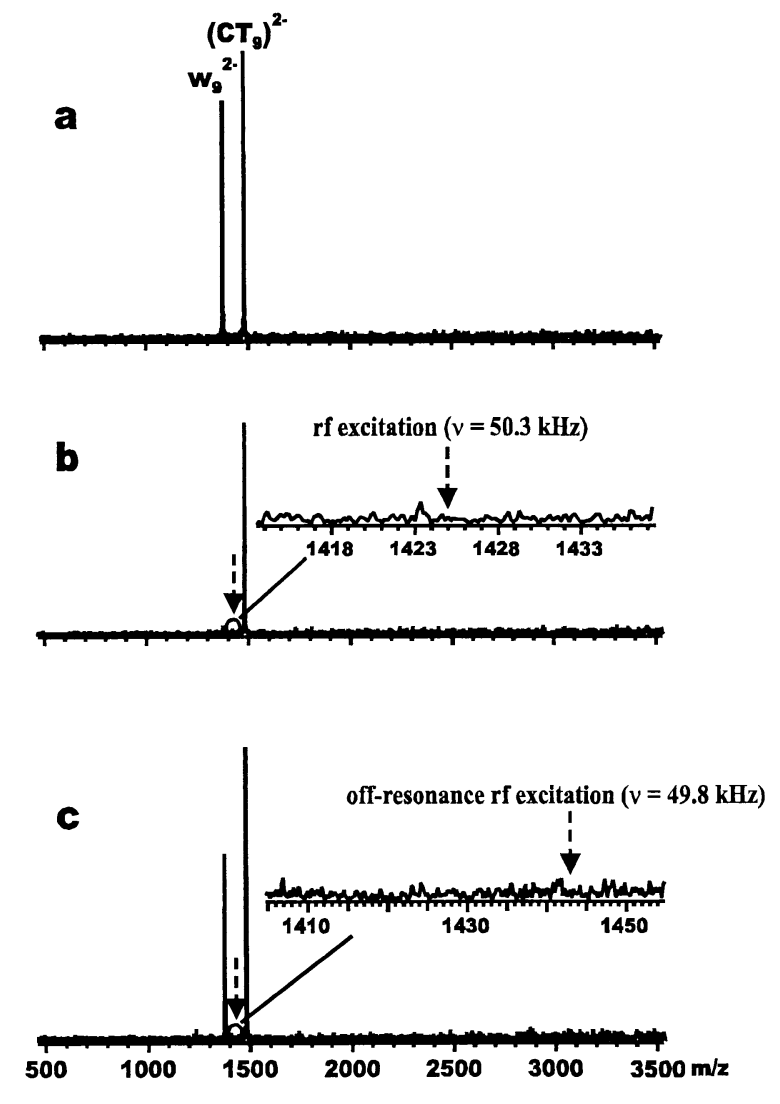

Figure 3. Blackbody infrared radiative dissociation spectra of the doubly deprotonated $\left(\mathrm{CT}_{9}\right)^{2-}$ anion (a) at $190.2{ }^{\circ} \mathrm{C}$ and a reaction time of $100 \mathrm{~s},(\mathbf{b})$ under the same conditions but with a continuous rf excitation at the frequency of the $(\mathrm{M}-\mathrm{CH})^{2-}$ ion $(\nu=50.3$ $\mathrm{kHz}$ ), (c) restoration of $\mathrm{w}_{9}^{2-}$ ion when the frequency of the $\mathrm{rf}$ excitation was moved slightly off-resonance from the $(\mathrm{M}-\mathrm{CH})^{2-}$ ion $(\nu=49.8 \mathrm{kHz})$

plots, obtained for $\left(\mathrm{AT}_{9}\right)^{2-}$ and $\left(\mathrm{T}_{9} \mathrm{~A}\right)^{2-}$, at four different temperatures are shown in Figure 5. The plots are linear and exhibit near zero intercepts, as expected for simple first-order reactions. Plots of similar quality were obtained for all of the anions investigated. The first-order rate constant was determined from the slope of a linear least squares fit of the kinetic data obtained at each temperature investigated.

$$
\begin{aligned}
& \ln \left(I_{R, \text { norm }, t}\right)=-k t \\
& I_{R, \text { norm }}=I_{R} /\left(I_{R}+\Sigma I_{P}\right)
\end{aligned}
$$

Arrhenius plots constructed from the temperature dependent rate constants for the loss of nucleobase are shown in Figure 6. For all of the ions investigated, linear plots were obtained. The kinetic data for the C-containing ions span a relatively small temperature range due to the very slow dissociation kinetics and an upper temperature limit of $\sim 190{ }^{\circ} \mathrm{C}$ for the apparatus used in this work. The Arrhenius activation energy $\left(E_{a}\right)$ and preexponential factor $(A)$ were obtained from the slope and y-intercept, respectively, of a linear least squares fit
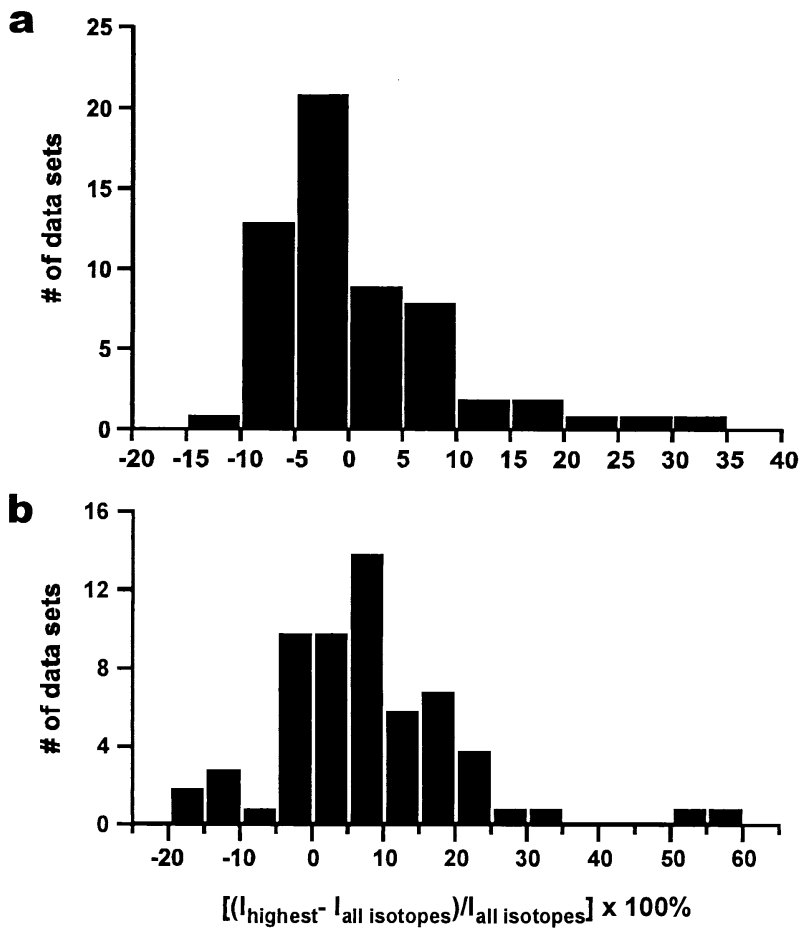

Figure 4. Distribution of the difference in $I_{R, \text { norm }}$ calculated using (i) the most abundant isotopic ion for the reactant and product ions $\left(I_{\text {highest }}\right)$ and (ii) the sum of the abundance of all the ions within each isotope envelope $\left(I_{\text {all isotopes }}\right)$ for $(\mathbf{a})\left(\mathrm{AT}_{9}\right)^{2-}$ and (b) $\left(\mathrm{T}_{5} \mathrm{AT}_{4}\right)^{2-}$.

of the temperature dependent kinetic data and the values are listed in Table 1 . Also included in Table 1 are values for the entropy of activation $\left(\Delta S^{\ddagger}\right)$, which corresponds to the difference in entropy between the transition state and the reactant, and which can be calculated from the corresponding $A$-factor using eq 4 . A negative $\Delta S^{\ddagger}$ indicates a loss of entropy in the transition state (i.e., a tight transition state), a positive value indicates a gain in entropy (i.e., a loose transition state), and a value close to zero corresponds to a reaction that is entropically neutral. The kinetic reactivity and the Arrhenius parameters are discussed below in terms of the nature and position of the nucleobase.

$$
A=(\mathrm{ekT} / \mathrm{h}) \exp \left(\Delta S^{\ddagger} / \mathrm{R}\right)
$$

From an inspection of the Arrhenius plots in Figure 6 it is clear that the dissociation kinetics and energetics for the loss of $\mathrm{XH}$ are sensitive to the nature of the $\mathrm{X}$ and its position within the ODN. Over the temperature range investigated, the kinetics for the loss of the purine bases $(A, G)$ are quite similar, within a factor of 5 , but they are a factor of $\sim 100$ faster than the kinetics for the loss of $\mathrm{CH}$. For base loss from the $5^{\prime}$ terminus, the trend in reactivity is: $A \approx G \gg C$; while for the $3^{\prime}$ terminus and internal position the trend is: $G>A \gg C$. The influence of position on reactivity is base dependent: A, $5^{\prime}$ terminus $\left(\equiv 5^{\prime}\right)>3^{\prime}>$ internal; $\mathrm{G}, 3^{\prime}>5^{\prime}>$ internal; 

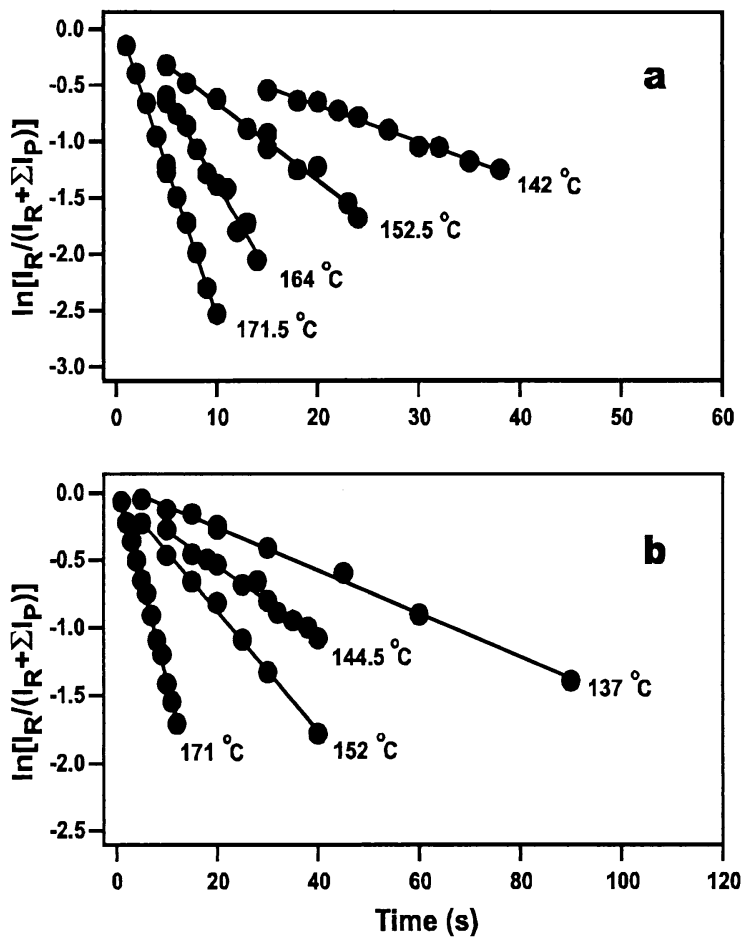

Figure 5. Dissociation kinetic data of (a) $\left(\mathrm{AT}_{9}\right)^{2-}$, (b) $\left(\mathrm{T}_{9} \mathrm{~A}\right)^{2-}$ obtained at the temperatures indicated.

$C, 5^{\prime}>$ internal $>3^{\prime}$. The dissociation $E_{a}$ values are also sensitive to the nature of the base, with the purine bases exhibiting lower values of $E_{a}$ than cytosine (A: 23-27, G: 26-30, C: $35-37 \mathrm{kcal} / \mathrm{mol}$ ) and, to some extent, its position. For the loss of $\mathrm{XH}$ from the $5^{\prime}$ and $3^{\prime}$ termini, the values of $E_{a}$ have the following order: $C>G>A$; while for $\mathrm{T}_{5} \mathrm{XT}_{4}$ the trend is: $\mathrm{C}>\mathrm{A}>\mathrm{G}$ (although the $E_{a}$ for $\mathrm{G}$ and $\mathrm{A}$ differ by only $1 \mathrm{kcal} / \mathrm{mol}$ ). It is important to note that the relative energetics for the loss of neutral $A$ and $G$ could not have been predicted from the relative reactivity of the bases observed over this temperature range. The $A$-factors (and values of $\Delta S^{\ddagger}$ ) are also sensitive to the nature and position of the nucleobase. For the loss of $\mathrm{AH}$ the $A$-factor range from $10^{10}$ to $10^{12} \mathrm{~s}^{-1}\left(\Delta S^{\ddagger}:-13\right.$ to $\left.-6 \mathrm{cal} / \mathrm{mol} \cdot \mathrm{K}\right)$; for the loss of $\mathrm{CH}$ the $A$-factors are $\sim 10^{14} \mathrm{~s}^{-1}\left(\Delta S^{\ddagger}: 3\right.$ to $\left.6 \mathrm{cal} / \mathrm{mol} \cdot \mathrm{K}\right)$; while for $\mathrm{GH}$, the A-factors range from $10^{12}$ to $10^{14} \mathrm{~s}^{-1}$ $\left(\Delta S^{\ddagger}:-8\right.$ to $\left.+4 \mathrm{cal} / \mathrm{mol} \cdot \mathrm{K}\right)$.

As previously noted, Williams and coworkers have reported Arrhenius parameters for the loss of neutral base from some doubly deprotonated 7-mers and it is of interest to compare their results [16] with the values obtained in the present work. The Arrhenius parameters reported for the loss of $\mathrm{AH}$ from $\mathrm{d}\left(\mathrm{A}_{7}\right)^{2-}, \mathrm{d}(\mathrm{AAT}-$ TAAT $)^{2-}$, and d(TTAATTA $)^{2-}$ in the previous study $\left(E_{a}\right.$ $\left.=23-26 \mathrm{kcal} / \mathrm{mol}, A=10^{10}-10^{11} \mathrm{~s}^{-1}\right)$ are in agreement with the present values. For the loss of $\mathrm{CH}$ and $\mathrm{GH}$ from $\mathrm{d}(\mathrm{CCGGCCG})^{2-}$ similar parameters were reported (GH: $30.1 \mathrm{kcal} / \mathrm{mol}, 10^{12.5} \mathrm{~s}^{-1}$; CH: $31.1 \mathrm{kcal} /$ mol, $\left.10^{13.1} \mathrm{~s}^{-1}\right)$. While the parameters measured for the loss of GH in the two studies are in reasonable agree- ment, the results from the loss of $\mathrm{CH}$ are not; the parameters measured in the present work are significantly larger.

The similarities and differences between the Arrhenius parameters measured in these two BIRD studies are noteworthy for two reasons. First, they highlight the influence of the chemical environment (i.e., context) on the reactivity of the bases. The similarity in the kinetics and energetics for the loss of $\mathrm{AH}$ from these $\mathrm{A}$ - and T-rich ODNs indicates that the environments of the reacting base are similar. In contrast, the reactivity of the cytosine bases is sensitive to the sequence of the ODN anions, with decreased reactivity in the T-rich oligomers compared to the d(CCGGCCG $)^{2-}$ ion. The influence of the chemical environment on the Arrhenius parameters is discussed in more detail below. Secondly, an important consideration when performing BIRD experiments on ions with molecular weights (MW) between $1-5 \mathrm{kDa}$ is whether the ions are thermalized, such that the Arrhenius parameters correspond to the values that would be obtained from experiments performed in the high pressure limit. The agreement between the Arrhenius parameters for the loss of AH from the 7-mers ( $\mathrm{MW} \sim 2 \mathrm{kDa}$ ) and 10-mers (MW $\sim 3 \mathrm{kDa}$ ) strongly suggests that the observed dissociation kinetics are not governed simply by the rate of photon absorption and that the 10 mers are in indeed in thermal equilibrium. This conclusion is reasonable given that Williams and coworkers have found that, within the same temperature window and for similar Arrhenius parameters, the dissociation kinetics of some protonated peptides with MWs of $\sim 2 \mathrm{kDa}$ were in the rapid energy exchange limit [20].

It is also worthwhile commenting on the apparent lack of agreement between the trend in base reactivity established in the present work and previous studies, even for ODNs with similar sequence. For example, the trend in kinetic reactivity observed in a CID study of doubly deprotonated T-rich 8-mers, wherein the reactive base occupied the 4 th and 5 th position, is $\mathrm{G}>\mathrm{C} \approx$ $\mathrm{A} \gg \mathrm{T}$ [11]. In the present work, the trend in average kinetic reactivity based on average Arrhenius parameters for the loss of each of the nucleobases (A: $E_{a}=25.2$ $\mathrm{kcal} / \mathrm{mol}, A=10^{11.5} ; \mathrm{G}: E_{a}=27.1 \mathrm{kcal} / \mathrm{mol}, A=10^{12.7}$; $\mathrm{C}: E_{a}=35.6 \mathrm{kcal} / \mathrm{mol}, A=10^{14.2}$ ) is: $\mathrm{G} \approx \mathrm{A}>\mathrm{C}$. The lack of agreement can be rationalized by the fact that internal energy distributions of the reacting ions produced with BIRD and CID are different. Unlike with the BIRD technique, wherein the ions adopt a Boltzmann distribution of internal energy at a known temperature, the energy distribution in the typical CID experiment is poorly defined. Furthermore, the fact that the loss of $\mathrm{T}$ has been observed with CID, but not with BIRD, indicates that higher internal energies are achieved with CID. Assuming that the Arrhenius parameters measured in the present work accurately describe the dissociation kinetics over a broad temperature range, it is possible to predict the trend in kinetic reactivity at temperatures higher than those studied here. Shown in 


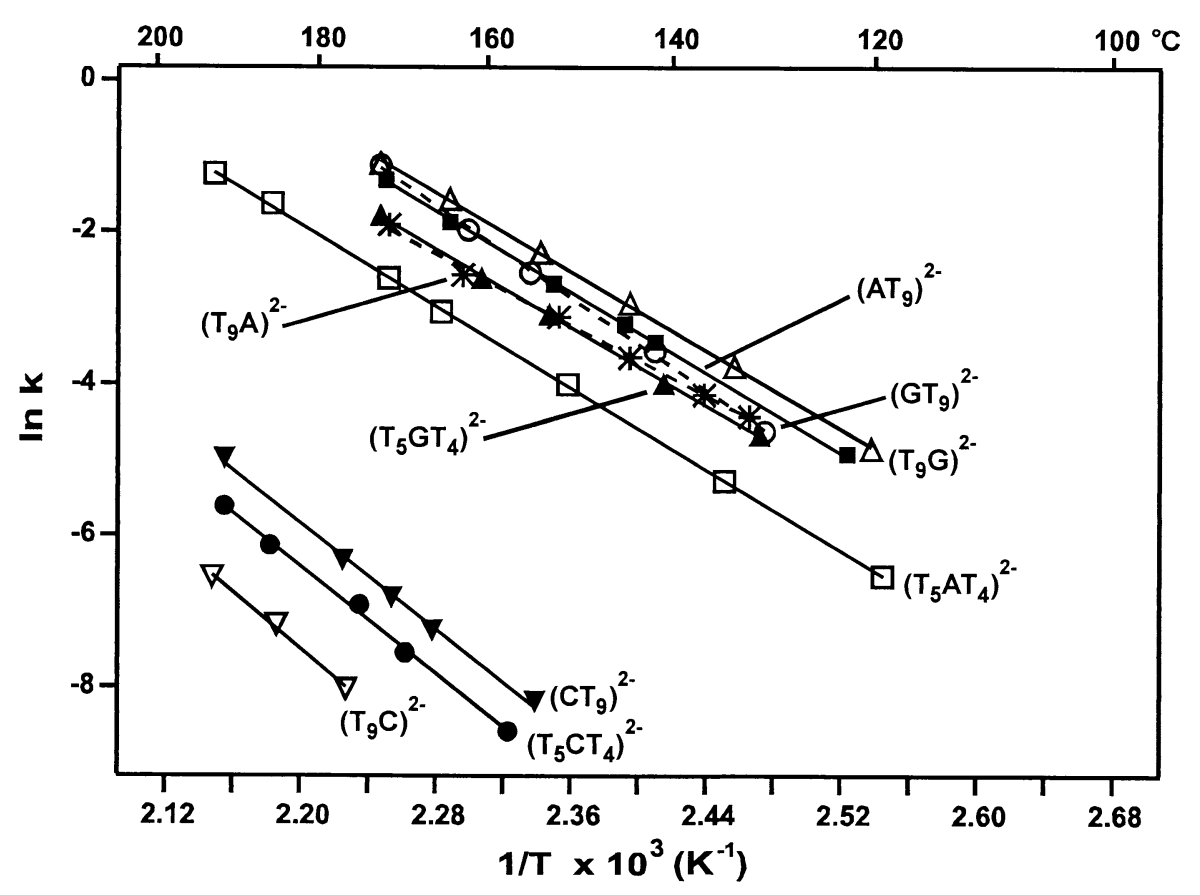

Figure 6. Arrhenius plots for the loss of neutral nucleobase from $\left(\mathrm{AT}_{9}\right)^{2-}$, (filled square); $\left(\mathrm{T}_{5} \mathrm{AT}_{4}\right)^{2-}$, (open square); $\left(\mathrm{T}_{9} \mathrm{~A}\right)^{2-}$, (star); $\left(\mathrm{GT}_{9}\right)^{2-}$, (open circle); $\left(\mathrm{T}_{5} \mathrm{GT}_{4}\right)^{2-}$, (filled triangle); $\left(\mathrm{T}_{9} \mathrm{G}\right)^{2-}$, (open triangle); $\left(\mathrm{CT}_{9}\right)^{2-}$, (filled inverted triangle); $\left(\mathrm{T}_{5} \mathrm{CT}_{4}\right)^{2-}$, (filled circle); $\left(\mathrm{CT}_{9}\right)^{2-}$, (open inverted triangle).

Figure 7 are Arrhenius plots, constructed with the average Arrhenius parameters, spanning temperatures of 100 to $700{ }^{\circ} \mathrm{C}$. Based on these plots, the predicted trend in reactivity at temperatures between 200 and 500 ${ }^{\circ} \mathrm{C}$ is $\mathrm{G}>\mathrm{A}>\mathrm{C}$. From 500 to $600{ }^{\circ} \mathrm{C}$ the trend is $\mathrm{G}>$ $\mathrm{C} \approx \mathrm{A}$, which is consistent with the results reported by Gross and coworkers for the 8-mers [11]. Therefore, collisional activation of the 8-mers studied with an ion trap appear to produce an internal energy distribution that is similar to that of thermalized ions with a temperature of 500 to $600{ }^{\circ} \mathrm{C}$. It is worthwhile to point out that at even higher temperatures, $>1000{ }^{\circ} \mathrm{C}$, the trend in kinetic reactivity is parallel to the trend in dissociation $E_{a}$ values: $C>G>A$. In other words, the most reactive base has the highest dissociation $E_{a}$. This observation highlights the need for caution when trying to infer trends in energetics from reactivity.

\section{Dissociation Mechanism and the Influence of Intramolecular Solvation}

As described above, the loss of a neutral nucleobase from a deprotonated ODN requires that proton transfer to the base accompany cleavage of the N-glycosidic bond, either before or in concert with bond cleavage, or after the base is lost in its deprotonated form. As the present study represents the first systematic study of the dissociation energies for loss of neutral base from specific positions, it is of interest to compare the mea-

Table 1. Arrhenius activation parameters for the loss of neutral nucleobase from some doubly deprotonated oligodeoxynucleotide anions containing a single reactive base

\begin{tabular}{ccrr}
\hline Oligodeoxynucleotide & $E_{a}(\mathrm{kcal} / \mathrm{mol})^{\mathrm{a}}$ & $A\left(\mathrm{~s}^{-1}\right)^{\mathrm{a}}$ & $\Delta S^{ \pm}(\mathrm{cal} / \mathrm{mol} \cdot \mathrm{K})^{\mathrm{b}}$ \\
\hline \hline$\left(\mathrm{AT}_{9}-2 \mathrm{H}\right)^{2-}$ & $25.9 \pm 0.2$ & $10^{12.1 \pm 0.1}$ & -6 \\
$\left(\mathrm{~T}_{5} \mathrm{AT}_{4}-2 \mathrm{H}\right)^{2-}$ & $26.7 \pm 0.2$ & $10^{12.0 \pm 0.1}$ & -6 \\
$\left(\mathrm{~T}_{9} \mathrm{~A}-2 \mathrm{H}\right)^{2-}$ & $23.0 \pm 0.6$ & $10^{10.5 \pm 0.3}$ & -13 \\
$\left(\mathrm{GT}_{9}-2 \mathrm{H}\right)^{2-}$ & $30.1 \pm 0.5$ & $10^{14.3 \pm 0.3}$ & 4 \\
$\left(\mathrm{~T}_{5} \mathrm{GT}_{4}-2 \mathrm{H}\right)^{2-}$ & $25.5 \pm 0.3$ & $10^{11.7 \pm 0.2}$ & -8 \\
$\left(\mathrm{~T}_{9} \mathrm{G}-2 \mathrm{H}\right)^{2-}$ & $25.7 \pm 0.3$ & $10^{12.2 \pm 0.2}$ & -5 \\
$\left(\mathrm{CT}_{9}-2 \mathrm{H}\right)^{2-}$ & $34.6 \pm 1.1$ & $10^{14.1 \pm 0.6}$ & 3 \\
$\left(\mathrm{~T}_{5} \mathrm{CT}_{4}-2 \mathrm{H}\right)^{2-}$ & $35.0 \pm 1.1$ & $10^{14.0 \pm 0.5}$ & 3 \\
$\left(\mathrm{~T}_{9} \mathrm{C}-2 \mathrm{H}\right)^{2-}$ & $37.2 \pm 2.3^{\mathrm{c}}$ & $10^{14.6 \pm 1.1 \mathrm{c}}$ & 6 \\
\hline
\end{tabular}

aErrors correspond to one standard deviation.

${ }^{\mathrm{b}} \Delta S^{ \pm}$values calculated at $423 \mathrm{~K}$ using eq 4 .

${ }^{\mathrm{c}}$ Arrhenius parameters determined from kinetic data that spanned only $25^{\circ} \mathrm{C}$. 


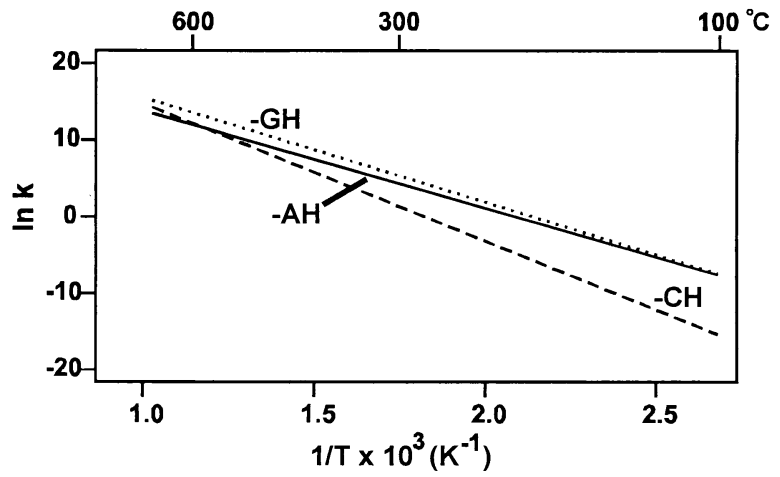

Figure 7. Extrapolated Arrhenius plots constructed with the average Arrhenius parameters for the loss of neutral nucleobase, A, (solid line), G, (dotted line) and C, (dashed line), from the doubly deprotonated 10-mer ODNs.

sured values of $E_{a}$ with the PA and $\Delta \mathrm{H}_{\text {acid }}$ of the free nucleobase and nucleoside to establish whether there is any correlation. The PAs of the free nucleobases have been established both experimentally and theoretically. Using the kinetic method, Greco and coworkers determined PA's for the deoxyribose nucleosides (dG 234.4 $>\mathrm{dA} 233.6 \approx \mathrm{dC} 233.2 \gg \mathrm{dT} 224.9 \mathrm{kcal} / \mathrm{mol})$ and the corresponding free nucleobases (G 227.4 > C $225.9>$ A $224.2 \gg \mathrm{T} 209.0 \mathrm{kcal} / \mathrm{mol}$ ) [21]. A similar trend in PAs was established for the nucleobases from theoretical calculations performed by Russo and coworkers: $G$ $230.3>$ C $229.1>$ A $225.8>$ T $208.8 \mathrm{kcal} / \mathrm{mol}$ [22]. Clearly, the trend in the dissociation $E_{a} \mathrm{~s}$ measured in the present work does not parallel the trend in PAs of either the nucleobases or the nucleosides, indicating that, if the base is protonated prior to cleavage of the glycosidic bond, additional factors influence the dissociation energetics. An alternative mechanism envisions the loss of the base initially in its deprotonated form $\left(\mathrm{X}^{-}\right)$, via a 1,2-elimination mechanism involving $\mathrm{H}^{-}$ abstraction at the $\mathrm{C}-2$ of the deoxyribose by the neighbouring deprotonated phosphate group [4, 8, 10, 23], followed by proton abstraction from the modified $\mathrm{ODN}$. If the differences in the strengths of the $\mathrm{N}$ glycosidic bond are similar to the differences in the nucleobase $\mathrm{N}-\mathrm{H}$ bond energies [24], the energy barrier for the reaction should reflect differences in the $\Delta \mathrm{H}_{\text {acid }}$ of the nucleobases. Marshall and coworkers have recently reported values of $\Delta \mathrm{H}_{\text {acid }}$, determined from ab initio calculations (MP2/6-31+G*/ $\left./ \mathrm{HF} / 6-31+\mathrm{G}^{*}\right)$, for the free nucleobases [25]. In all cases, the hydrogen at the linkage nitrogen was found to be the most acidic, with a $\Delta \mathrm{H}_{\text {acid }}$ of $\sim 327 \mathrm{kcal} / \mathrm{mol}$ for $\mathrm{A}, \mathrm{G}$, and $\mathrm{T}$ and 337 $\mathrm{kcal} / \mathrm{mol}$ for C. If the base is lost in its deprotonated form, and in the absence of other effects, the dissociation energies for the loss of $A, G$, and $T$ should be similar but significantly higher for $C$. While it could be argued that the general trend in $E_{a}$ values for $\mathrm{A}, \mathrm{G}$ and $\mathrm{C}$ are more or less in agreement with the trend in the $\Delta \mathrm{H}_{\text {acid }}$ values, the unusual stability of $\mathrm{T}$ cannot be explained by an unusually high $\Delta \mathrm{H}_{\text {acid }}$. From this analysis it can be concluded that the differences in the dissociation energies for the bases do not arise simply from differences in the acid/base properties of the nucleobases in the gas phase.

The absence of correlation between the dissociation $E_{a}$ values and the gas phase acid/base properties of the bases, in addition to the influence of sequence and position on the Arrhenius parameters measured for base loss, could be the result of (1) different dissociation mechanisms, which depend on the nature and position of the base, and (2) the presence of intramolecular interactions, perhaps hydrogen bonds and stacking interactions between nucleobases or hydrogen bonds (ionic or neutral) between the base and phosphate groups. While the possibility of multiple mechanisms cannot be discounted, it is, in our opinion, unlikely that the influence of sequence and position on the Arrhenius parameters arises simply from operation of different mechanisms. Instead, differential solvation of the reactive base is a more plausible explanation for the variability in the Arrhenius parameters.

At present there are few data available on the conformation of ODN anions in gas phase. Recently, Gidden and Bowers, using ion mobility measurements and molecular modeling, identified base-base interactions (stacking and hydrogen bonding) in the deprotonated dinucleotide anions [26]. Evidence of extensive intramolecular interactions in larger ODN anions has also been obtained from collision cross section measurements $[27,28]$. Clemmer and coworkers measured collision cross sections and performed molecular dynamics simulations on $\mathrm{d}\left(\mathrm{T}_{10}\right)^{\mathrm{n}-}$ ions, where $n=2$ to 6 [26]. It was observed that the collision cross section increased with charge state, a result that was explained by Coulombic repulsion-induced unfolding of the anion. Molecular modeling of anions with different charge states and distributions suggested that the $\mathrm{d}\left(\mathrm{T}_{10}\right)^{\mathrm{n}-}$ ions favour compact globular structures involving extensive base stacking and hydrogen bonds at low charge states (i.e., $n=-2,-3$ ) and elongated structures at higher charge states. Douglas and coworkers recently reported collision cross sections for some deprotonated 28-, 40-, and 55-mers with varying charge states [28]. At lower charge states, the ions were found to have globular or spherical structures, while at higher charge states the ions adopted an extended conformation.

Based on the aforementioned studies, it is reasonable to expect intramolecular interactions to be present in the doubly deprotonated 10-mers investigated in the present work. Although it is impossible to identify specific interactions, some insight into their influence on the dissociation process can be obtained from the magnitude of the Arrhenius parameters. Intramolecular solvation of the reactive nucleobase or the charged groups (assuming base loss proceeds by a charge directed mechanism) will contribute to the dissociation energy since these interactions must be broken for the base to be lost (Figure 8). Consequently, the observed $E_{a}$ (i.e., $E_{a, \text { obs }}$ ) will reflect the contribution of the intrinsic 


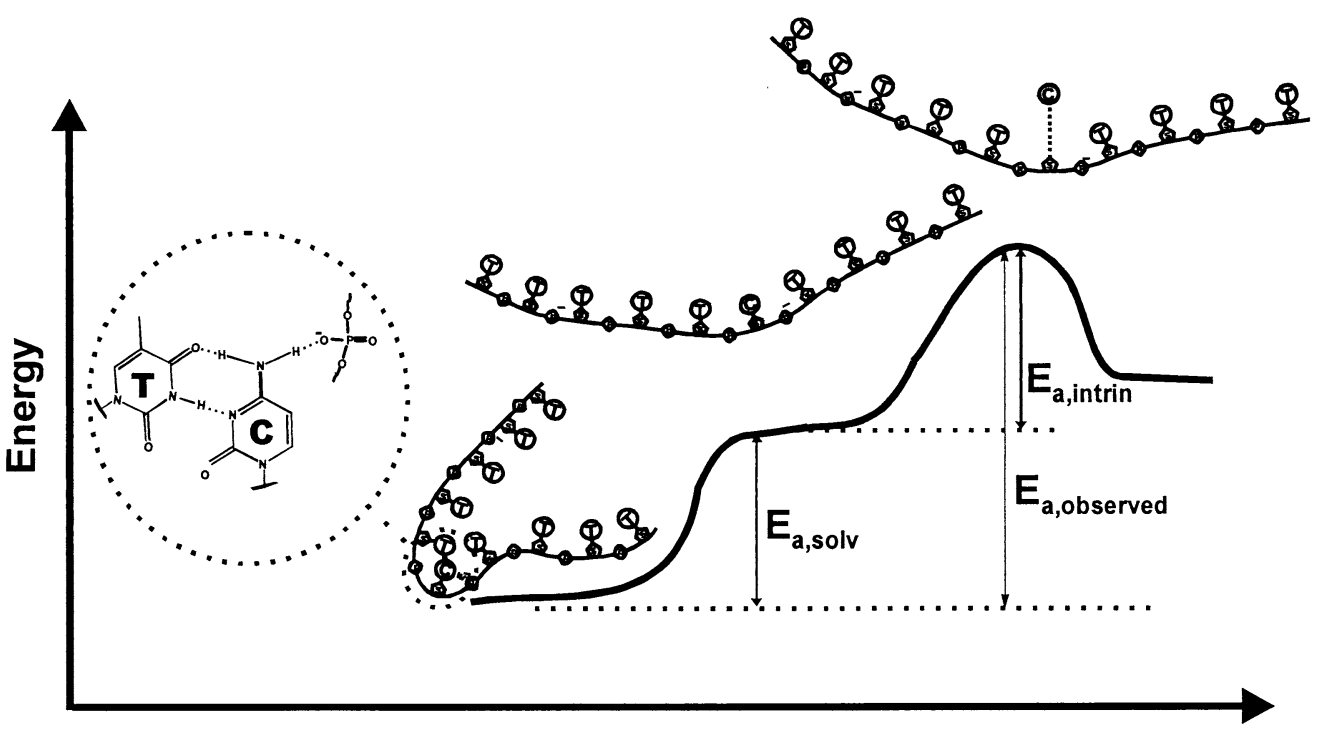

Reaction coordinate

Figure 8. Hypothetical energy diagram for the loss of a nucleobase from a doubly deprotonated ODN ion. The observed $E_{a}$ contains the energy required to break intramolecular solvation of the base $\left(E_{a, \text { solv }}\right)$ and the energy required to cleave the glycosidic bond $\left(E_{a, \text { intrin }}\right)$.

dissociation energy $\left(E_{a, \text { intrin }}\right)$ plus the energy required to overcome the intramolecular interactions $\left(E_{a, \text { solv }}\right)$. Unfortunately, it is not possible to separate the contribution of $E_{a, \text { intrin }}$ and $E_{a, \text { solv }}$ to the values of $E_{a}$ measured in the present work. However, cleavage of the intramolecular interactions, in addition to the glycosidic bond, during the dissociation process will also influence the magnitude of the $A$-factors and $\Delta S^{\ddagger}$. Our laboratory has previously shown that the dissociation kinetics of noncovalent protein complexes, stabilized by an array of intermolecular hydrogen bonds, are characterized by large $A$-factors (and $\Delta S^{f^{\prime}} s$ ) $[19,29]$. These results are general and have been attributed to the cleavage of the non-covalent interactions and concomitant softening of numerous vibrational modes along the reaction coordinate. Therefore, the observed $\Delta S^{\ddagger}$ will reflect the contribution of the intrinsic entropy of activation $\left(\Delta S^{\ddagger}{ }_{\text {intrin }}\right)$ plus the gain in entropy resulting from the cleavage of the intramolecular interactions $\left(\Delta S^{\ddagger}{ }_{\text {solv }}\right)$. If all of the bases are lost via the same mechanism, and in the absence of internal solvation, the magnitude of the $\Delta S^{\ddagger}$ should be similar in all cases. Consequently, differences in $\Delta S^{\ddagger}$ must reflect differences in $\Delta S^{\ddagger}$ solv, the extent to which the reactive base is internally solvated. Proceeding from this premise, the negative values of $\Delta S^{\ddagger}$ determined for the A-containing ions suggest that, within the T-rich ODNs, adenine participates in the fewest or the weakest intramolecular interactions. This is perhaps surprising given the propensity of these bases to participate in Watson-Crick intermolecular hydrogen bonding in DNA duplexes. That similar Afactors were measured for the A-rich 7-mer [16] further suggests that adenine-adenine interactions are not prevalent. In contrast, the larger (and positive) $\Delta S^{\ddagger}$ values determined for the loss of $\mathrm{CH}$ indicate a greater ability of cytosine to participate in intramolecular interactions with the thymine bases or the backbone. The range of $\Delta S^{\ddagger}$ values (both positive and negative) measured for the loss of GH indicate that extent of intramolecular solvation of guanine depends on its position within the ODN. Beauchamp and coworkers have previously reported that the guanine amino group can form an ionic hydrogen bond with the adjacent 3 ' deprotonated phosphate group [10]. It is also interesting to note that the larger $\Delta S^{\ddagger}$ (and $E_{a}$ ) measured for the loss of GH from the terminal $5^{\prime}$ position is consistent with the previous observation that, in this position, $\mathrm{G}$ is stabilized by a hydrogen bond with the $\mathrm{C}-5 \mathrm{OH}$ group of the deoxyribose group [30].

Our laboratory is currently determining Arrhenius parameters for the dissociation of larger T-rich ODN anions to determine whether the trends in the dissociation $E_{a}$ and $\Delta S^{\ddagger}$ values measured for the 10-mers are general.

\section{Conclusions}

The thermal decomposition of a series of T-rich doubly deprotonated ODN 10-mers with a single reactive nucleobase has been studied using the BIRD technique. From the temperature dependence of the dissociation kinetics, Arrhenius activation parameters for the loss of specific nucleobases have been obtained for the first time. The dissociation kinetics and energetics for the loss of a nucleobase from a given position within the ODNs are found to be sensitive to the identity of the base. The trend in values of $E_{a}$ for the loss of base from the $5^{\prime}$ and $3^{\prime}$ termini is: $A<\mathrm{G}<\mathrm{C}$, while for loss of 
base from an internal position the trend is: $A \approx G<C$. The $E_{a}$ for the loss of a given base is sensitive to the location of the base within the ODN. The trend in the energetic data does not provide support for any of the commonly proposed mechanisms for the loss of neutral nucleobase. However, the results do indicate that the differences in dissociation $E_{a}$ values do not originate solely from differences in acidic or basic character of the bases. Instead, the ability of the nucleobases to participate in intramolecular interactions appears to influence the dissociation energetics and dynamics. These results highlight the complexity of the base loss reaction and the difficulty in devising experiments to elucidate the mechanism(s).

\section{Acknowledgments}

Financial support was provided by the Natural Sciences and Engineering Research Council of Canada (NSERC). The authors thank E.N. Kitova and A.T. Blades for helpful comments during the preparation of the manuscript.

\section{References}

1. Zhu, L.; Parr, G. R.; Fitzgerald, M. C.; Nelson, C. M.; Smith, L. M. J. Am. Chem. Soc. 1995, 117, 6048-6056.

2. McLuckey, S. A.; Vaidyanathan, G.; Habibi-Goudarzi, S. J. Mass Spectrom. 1995, 30, 1222-1229.

3. Phillips, D. R.; McCloskey, J. A. Int. J. Mass Spectrom. Ion Processes 1993, 128, 61-82.

4. Barry, J. P.; Vouros, P.; Schepdael, A. V.; Law, S.-J. J. Mass Spectrom. 1995, 30, 993-1006.

5. Bartlett, M. G.; McCloskey, J. A.; Manalili, S.; Griffey, R. H. J. Mass Spectrom. 1996, 31, 1277-1283.

6. McLuckey, S. A.; Vaidyanathan, G. Int. J. Mass Spectrom. Ion Processes 1997, 162, 1-16.

7. McLuckey, S. A.; Van Berkel, G. J.; Glish, G. L. J. Am. Soc. Mass Spectrom. 1992, 3, 60-70.

8. McLuckey, S. A.; Habibi-Goudarzi, S. J. Am. Chem. Soc. 1993, 115, 12085-12095.

9. Little, D. P.; Aaserud, D. J.; Valaskovic, G. A.; McLafferty, F. W. J. Am. Chem. Soc. 1996, 118, 9352-9359.
10. Rodgers, M. T.; Campell, S.; Marzluff, E. M.; Beauchamp, J. L. Int. J. Mass Spectrom. Ion Processes 1994, 137, 121-149.

11. Wan, K. X.; Gross, M. L. J. Am. Soc. Mass Spectrom. 2001, 12, 580-589.

12. Luo, H.; Lipton, M. S.; Smith, R. D. J. Am. Soc. Mass Spectrom. 2002, 13, 195-199.

13. Wan, K. X.; Gross, J.; Hillenkamp, F.; Gross, M. L. J. Am. Soc. Mass Spectrom. 2001, 12, 193-205.

14. Wang, Z.; Wan, K. X.; Ramanathan, R.; Taylor, J. S.; Gross, M. L. J. Am. Soc. Mass Spectrom. 1998, 9, 683-691.

15. Gross, J.; Hillenkamp, F.; Wan, K. X.; Gross, M. L. J. Am. Soc. Mass Spectrom. 2001, 12, 180-192.

16. Klassen, J. S.; Schnier, P. D.; Williams, E. R. J. Am. Soc. Mass Spectrom. 1998, 9, 1117-1124.

17. Ho, Y.; Kebarle, P. Int. J. Mass Spectrom. Ion Processes 1997, 165, 433-455.

18. Hannis, J. C.; Muddiman, D. C. Int. J. Mass Spectrom. 2002, 219, 139-150.

19. Felitsyn, N.; Kitova, E. N.; Klassen, J. S. Anal. Chem. 2001, 73, 4647-4661.

20. Price, W. D.; Williams, E. R. J. Phys. Chem. A 1997, 101, 8844-8852.

21. Greco, F.; Liguori, A.; Sindona, G.; Uccella, N. J. Am. Chem. Soc. 1990, 112, 9092-9096.

22. Russo, N.; Toscano, M.; Grand, A.; Jolibois, F. J. Comp. Chem. 1998, 19, 989-1000.

23. Cerny, R. L.; Gross, M. L.; Grotjahn, L. Anal. Biochem. 1986, 156, 424-435.

24. Chen, E. S. D.; Chen, E. C. M.; Sane, N. Biochem. Biophys. Res. Commun. 1998, 246, 228-230.

25. Freitas, M. A.; Shi, S. D.-H.; Hendrickson, C. L.; Marshall, A. G. J. Am. Chem. Soc. 1998, 120, 10187-10193.

26. Gidden, J.; Bowers, M. T. Eur. Phys. J. D 2002, 20, 409-419.

27. Hoaglund, C. S.; Liu, Y.; Ellington, A. D.; Pagel, M.; Clemmer, D. E. J. Am. Chem. Soc. 1997, 119, 9051-9052.

28. Moradian, A.; Scalf, M.; Westphall, M. S.; Smith, L. M.; Douglas, D. J. Int. J. Mass Spectrom. 2002, 219, 161-170.

29. Kitova, E. N.; Bundle, D. R.; Klassen, J. S. J. Am. Chem. Soc. 2002, 124, 5902-5913.

30. Nir, E.; Imhof, P.; Kleinermanns, K.; de Vries, M. S. J. Am. Chem. Soc. 2000, 122, 8091-8092.

31. Marshall, A. G.; Grosshans, P. B. Anal. Chem. 1991, 63, 215A229A. 